\title{
Effectiveness of the Strengthening Families Programme 10-14 in Poland for the prevention of alcohol and drug misuse: protocol for a randomized controlled trial
}

\author{
Katarzyna Okulicz-Kozaryn ${ }^{1}$ and David R Foxcroft ${ }^{2 *}$
}

\begin{abstract}
Background: Alcohol and other drug use and misuse is a significant problem amongst Polish youth. The SFP10-14 is a family-based prevention intervention that has positive results in US trials, but questions remain about the generalizability of these results to other countries and settings.

Methods/Design: A cluster randomized controlled trial in community settings across Poland. Communities will be randomized to a SFP10-14 trial arm or to a control arm. Recruitment and consent of families, and delivery of the SFP10-14, will be undertaken by community workers. The primary outcomes are alcohol and other drug use and misuse. Secondary (or intermediate) outcomes include parenting practices, parent-child relations, and child problem behaviour. Interview-based questionnaires will be administered at baseline, 12 and 24 months.
\end{abstract}

Discussion: The trial will provide information about the effectiveness of the SFP10-14 in Poland.

Trial registration: International Standard Randomised Controlled Trial Number: ISRCTN89673828

\section{Background}

The European Union (EU) is the heaviest drinking region of the world, drinking 11 litres of pure alcohol per adult each year [1]. More than 1 in 4 deaths among men (aged 15-29 years) and 1 in every 10 deaths among young women in the EU is alcohol related [2]. Young people (aged 15-24 years) are responsible for a high proportion of this burden, with over $25 \%$ of youth male mortality and approximately $10 \%$ of young female mortality being due to alcohol [1]. Sparse information exists on the extent of social harm in young people, despite the fact that a third of a million (6\%) 15-16 year old school students in the EU report engaging in fights, and $200,000(4 \%)$ report unprotected sex, due to their own drinking [1].

Alcohol and other drug use increases markedly between the ages of 11 and 15 years amongst young people in Poland. Between the ages of 11 and 15 the proportion of those who have ever smoked increases from $12 \%$ to

\footnotetext{
* Correspondence: david.foxcroft@brookes.ac.uk

${ }^{2}$ Oxford Brookes University, Oxford, OX3 OFL, UK

Full list of author information is available at the end of the article
}

$59 \%$. At age $11,10 \%$ of 11 -year-olds report that they have ever been drunk, and this increases to 53\% amongst 15 year-olds. Moreover, 18\% of Polish youth report lifetime cannabis use [3]. Early alcohol and other drug use is associated with a range of subsequent adverse health and social outcomes [4-11].

The Strengthening Families Program 10-14 (SFP10-14) is a US-developed family-based intervention for preventing alcohol and other drug use and problems amongst young people. It has been evaluated in two large-scale randomized controlled trials in Iowa, USA [12-16] and has informed the development of a family-based intervention for African American families evaluated in a large randomized controlled trial in rural Georgia, USA [17-19]. Several systematic reviews have highlighted the promising results from these trials but also note the question of whether this US-developed intervention will be applicable in other countries and settings [20-25].

\section{Aims of the project}

The aim of the trial is to assess the effectiveness of the Polish version of the SFP10-14 ("Program Wzmacniania 
Rodziny") when compared with a control group, in a large randomized controlled trial in Poland.

The objectives of this trial are:

- To examine the effectiveness of the SFP10-14 in promoting positive parenting practices in parents of 10-14 year-olds in Poland

- To examine the effectiveness of the SFP10-14 in promoting positive parent-child relations amongst families with 10-14 year-olds in Poland

- To examine the effectiveness of the SFP10-14 in reducing problem behaviour amongst 10-14 year-olds in Poland

- To examine the effectiveness of the SFP10-14 in preventing alcohol and drug use and misuse amongst 10-14 years-olds in Poland

\section{Methods/Design \\ Design}

A parallel group cluster randomized controlled trial where communities will be randomly assigned, with concealed allocation, to one of two groups, with a 1:1 allocation ratio. Communities in the intervention arm will participate in SFP10-14 group sessions; communities in the control arm of the trial will receive information leaflets for families. All families recruited into the trial will be assessed at baseline and at 12 and 24 months follow-up. Two years after baseline data collection, families from control communities will be offered the opportunity to participate in SFP10-14.

\section{Ethics}

Research undertaken in Poland funded by the National Bureau for Drug Prevention is reviewed by independent experts, and this independent review process covers scientific and any ethical issues that are identified by the independent reviewers. Ethics Committee approval for data collection was obtained from "Komisji Bioetycznej przy Instytut Psychiatrii I Neurologii W Warszawa" (Ethics Committee of the Warsaw Institute for Psychiatry and Neurology). Each family recruited into the trial receives an information sheet describing the trial and data collection procedures before giving their written and signed consent to participate. Consent was obtained from parent(s) and, separately, from children.

\section{Setting and participants}

Eligible participants are families with 10-14 year-old children from community settings across Poland. In all families at least one parent should agree to participate. If two children from the same family are involved in the intervention group then both parents will be asked to participate in SFP10-14 group sessions.

\section{Recruitment}

Communities who have expressed an interest in the SFP10-14 will be approached in 2010 to participate in the trial. Information about the SFP10-14 has been disseminated throughout Poland via conferences, journal articles, information bulletins and personal contact. Within communities, families will be recruited by community workers. Family recruitment will take place through community agencies, schools and via information leaflets and personal contact.

\section{Randomization}

Randomization occurs after communities have consented to participate in the trial. Simple randomization of community to intervention or control arm will be undertaken by the lead investigator drawing names out of a hat in a concealed allocation format.

\section{Intervention}

The SFP10-14 is a video based programme delivered by trained facilitators that includes parents/guardians and children learning together [26-29]. The 7-week program is delivered over 7 -sessions, with 4 optional booster sessions available several months later. The weekly sessions last two to three hours: in the first hour parallel groups of children and parents from up to 15 families develop their understanding and skills, led by parent and child group facilitators; in the second hour, parents and children come together in family units to practice the principles they have learned. The remaining time is spent in logistics, meals and enjoyable family activities. The programme is highly structured with detailed manuals, videos and activities whilst at the same time being highly interactive [26-29].

\section{Outcome measures}

Alongside demographic questions (including family size and structure, parental education, work status, disposable income) we have carefully selected validated instrument measures/scales:

\section{Primary outcomes}

- Alcohol, cigarette and other drugs: age of first use, lifetime prevalence, 30-days (not other drugs) and 12-month prevalence

- Alcohol use without parent permission

- Drunkenness/binge drinking in past 30 days

\section{Secondary outcomes}

- General Child Management [30-32]

- Parent - Child Affective Quality [30,32]

- Aggressive and Hostile Behaviors in Interactions [30,32] 
- Intervention-targeted Parenting Behavior scale [32,33]

- Index of Aggressive and Destructive Conduct [34,35]

- Family aggressiveness [36]

- Family togetherness [36]

- Maternal support [36]

- Parental monitoring [36]

- Time spent with Mother/Father [36]

- Family Rituals

- Family Life Questionnaire [37]

- Truancy

- School behavior grades

- Grade Point Average

- Strengths and Difficulties Questionnaire [38,39]

- Parental alcohol and cigarette use

\section{Data collection}

Data are collected at baseline, 12 and 24 months. Interview-based questionnaires will be completed by parents and independently by children in separate rooms. In the control group one parent (or both if they express an interest) will complete the questionnaire, and if there are two children in the target age range (10-14) only the youngest will be asked to complete the questionnaire.

\section{Blinding}

Due to the nature of the intervention blinding of participants, SFP10-14 facilitators and data collectors is not possible.

\section{Sample size calculation}

No formal sample size calculation was undertaken but funding was requested for a sample size $(\mathrm{N}=600$ families) which was similar to that reported in other trials of the SFP10-14 [12-16]. These other trials have reported SFP10-14 effectiveness for reducing a number of risky behaviours amongst young people, including alcohol and drug use and misuse and other behavioural problems.

\section{Analyses}

Clustering at the community and family level will be taken account of in multi-level data analysis. Statistical tests of difference in proportions or mean difference tests (or non-parametric equivalents) will be used to examine differences between intervention and control groups. Based on pilot study results [40], data will be analyzed for the whole sample and by several sub-group analyses: child age group (10-12; 13-14); family problems (violence, chronic illness, substance use problems, financial problems etc.; low vs high severity); child behaviour and emotional problems (low vs high severity). All analyses will be on an intent-to-treat basis, and both completed case analysis and multiple imputation analysis will be undertaken.

\section{Discussion}

Social and cultural differences between the United States and European countries mean that positive results from US prevention trials may not translate to other countries. The Strengthening Families Programme 10-14 (SFP10-14) has been evaluated in several randomized controlled trials in rural Iowa in the United States and shown to be effective for delaying alcohol and drug initiation, but the extent that these results are applicable to other settings is not known.

The long-term goal of the SFP10-14 is reduced substance misuse and behaviour problems during adolescence. This is achieved through improved parental nurturing and limit setting skills, improved communication skills for both parents and young people and development of young people's pro-social skills. These parenting skills and relationship factors are culturally universal so, in principle, the intervention should be applicable to other settings.

This cluster randomized controlled trial of the SFP10-14 is one of the first trials to test this intervention outside of the United States. As such, this is an important replication that will examine the transferability and applicability of this intervention in an international context. Evidence about the effectiveness of the SFP10-14 in a European setting might lead to better family-based prevention programmes across Europe or, conversely, will provide much needed insight into the applicability of US programmes to other countries.

\section{Abbreviations}

SFP10-14: Strengthening Families Programme for Young People aged 10-14 and their Parents/Carers; US: United States; USA: United States of America.

\section{Competing interests}

Foxcroft declares that Oxford Brookes University has a training consultancy service for the SFP10-14. Okulicz-Kozaryn declares that she has received payment for training SFP10-14 facilitators.

\section{Acknowledgements}

The Polish National Bureau for Drug Prevention funded the research project. Diageo PLC provided support for the training and delivery of the SFP10-14. Maraton Foundation co-ordinated delivery of the SFP10-14 in locations throughout Poland. No funder has had any role in the preparation of the manuscript or the decision to submit.

\section{Author details}

${ }^{1}$ Institute of Psychiatry and Neurology, Sobieskiego 9, 02-957, Warsaw, Poland. ${ }^{2}$ Oxford Brookes University, Oxford, OX3 OFL, UK.

\section{Authors' contributions}

All authors have contributed to the development of this protocol. $\mathrm{KO}-\mathrm{K}$ led on methodological development and analytical strategy and consulted DF on these aspects. KO-K and DF wrote the first draft together and all authors have approved this manuscript.

Received: 7 February 2012 Accepted: 2 May 2012

Published: 2 May 2012

\section{References}

1. Anderson P, Baumberg B: Alcohol in Europe. 2006, Institute of Alcohol Studies, [http://ec.europa.eu/health-eu/news_alcoholineurope_en.htm (accessed 08/03/2011)]. 
2. Rehm J, Room R, van den Brink W, Jacobi F: Alcohol use disorders in EU countries and Norway: an overview of the epidemiology. Eur Neuropsychopharmacol 2005, 15:377-388.

3. Mazur J, Woynarowska B, Kololo H: Zdrowie subiektywne, styl życia i środowisko psychospołeczne młodzieży szkolnej w Polsce. Technical report from HBSC, 2006 [ln Polish]. Warszawa: Instytut Matki i Dziecka, Zakład Epidemiologii; 2007.

4. American Medical Association: Harmful consequences of alcohol use on the brains of children, adolescents, and college students. 2004, American Medical Association, [http://www.ama-assn.org/ama1/pub/upload/mm/388/ harmful_consequences.pdf] (accessed 08/03/2011).

5. Dawson DA, Goldstein RB, Chou SP, Ruan WJ, Grant BF: Age at first drink and the first incidence of adult-onset DSM-IV alcohol use disorders. Alcohol Clin Exp Res 2008, 32:2149-2160.

6. Hingson $\mathrm{R}$, Heeren $\mathrm{T}$, Winter MR, Wechsler $\mathrm{H}$ : Early age of first drunkenness as a factor in college students' unplanned and unprotected sex attributable to drinking. Pediatrics 2003, 111:34-41.

7. Hingson R, Heeren T, Zackos R, Winter M, Wechsler H: Age of first intoxication, heavy drinking, driving after drinking, and risk of unintentional injury among U.S. college students. J Stud Alcohol 2003, 64:23-31.

8. Hingson RW, Heeren T, Winter MR: Age at drinking onset and alcohol dependence: age at onset, duration, and severity. Arch Pediatr Adolesc Med 2006, 160(7):739-746.

9. Pitkanen $T$, Lyyra A-L, Pulkkinen $L$ : Age of onset of drinking and the use of alcohol in adulthood: a follow-up study from age 8-42 for females and males. Addiction 2005, 100:652-661.

10. Warner LA, White HR: Longitudinal effects of age at onset and first drinking situations on problem drinking. Subst Use Misuse 2003, 38:1983-2016.

11. Zakrajsek JS, Shope JT: Longitudinal examination of underage drinking and subsequent drinking and risky driving. J Safety Res 2006, 37:443-451

12. Spoth R, Randall GK, Shin C, Redmond C: Randomized study of combined universal family and school preventive interventions: patterns of longterm effects on initiation, regular use, and weekly drunkenness. Psychol Addict Behav 2005, 19(4):372-381.

13. Spoth R, Redmond C, Shin C: Randomized trial of brief family interventions for general populations adolescent substance use outcomes 4 years following baseline. J Consult Clin Psycho/ 2001, 69(4):1-15.

14. Spoth R, Redmond C, Shin C, Azevedo K: Brief family intervention effects on adolescent substance initiation school-level growth curve analyses 6 years following baseline. J Consult Clin Psychol 2004, 72(3):535-542.

15. Spoth RL, Clair S, Shin C, Redmond C: Long-term effects of universal preventive interventions on metamphetamine use among adolescents. Arch Pediatr Adolesc Med 2006, 160:876-882.

16. Spoth RL, Redmond C, Lepper $\mathrm{H}$ : Alcohol initiation outcomes of universal family-focused preventive interventions one- and two year follow-ups of a controlled study. J Stud Alcohol 1999, 13:103-111.

17. Brody GH, Kogan SM, Chen YF, McBride Murry V: Long-term effects of the strong African American families program on youths' conduct problems. $J$ Adolesc Health 2008, 43(5):474-481.

18. Brody GH, Murry VM, Kogan SM, Gerrard M, Gibbons FX, Molgaard V, Brown AC, Anderson T, Chen YF, Luo Z, Wills TA: The strong African American families program: a cluster-randomized prevention trial of long-term effects and a mediational model. J Consult Clin Psychol 2006, 74(2):356-366.

19. Brody GH, Murry VM, McNair LCYFGFX, Gerrard M, Ashby WT: Linking changes in parenting to parent-child relationship quality and youth self-control: the strong African American families program. J ResAdolesc 2005, 15(1):47-69.

20. Foxcroft D, Ireland D, Lister-Sharp DJ, Lowe G, Breen R: Primary prevention for alcohol misuse in young people. Cochrane Database Syst Rev 2002(3). doi:10.1002/14651858.CD003024. Art. No.: CD003024.

21. Foxcroft DR. Alcohol misuse prevention for young people: a rapid review of recent evidence. 2006, WHO Technical Report, [http://shsc.brookes.ac.uk/ images/pdfs/research/profiles/david_foxcroft/WHO_Technical_Report_foxcroft. pdf] (accessed 08/03/2011).

22. Foxcroft DR, Ireland D, Lister-Sharp D, Lowe G, Breen R: Longer-term primary prevention for alcohol misuse in young people: a systematic review. Addiction 2003, 98:397-411.

23. Foxcroft DR, Lister-Sharp D, Lowe G: Alcohol misuse prevention for young people: a systematic review reveals methodological concerns and lack of reliable evidence of effectiveness. Addiction 1997, 92(5):531-537.

24. Babor T, Caulkins J, Edwards G, Fischer B, Foxcroft D, Humphreys K, Obot I, Rehm J, Reuter P, Room R: Drug policy and the public good. Oxford: Oxford University Press; 2010.
25. Gates S, McCambridge J, Smith LA, Foxcroft DR: Interventions for prevention of drug use by young people delivered in non-school settings. Cochrane Database Syst Rev 2006, Issue 1. Art. No.: CD005030. doi:10.1002/14651858.CD005030.pub2.

26. Molgaard V, Spoth R: Strengthening Families Program for young adolescents: Overview and outcomes. In Innovative Mental Health Programs for Children. Edited by Pfeiffer S, Reddy L. Binghampton: Haworth Press; 2001:15-29.

27. Molgaard V, Spoth R, Redmond C: Competency training: The Strengthening Families Program for Parents and Youth 10-14. OJJDP Juvenile Justice Bulletin (NCJ 182208). Washington: U.S. Department of Justice, Office of Juvenile Justice and Delinquency Prevention, 2000.

28. Allen D, Coombes L, Foxcroft DR: Cultural accommodation of the strengthening families programme 10-14: UK Phase I study. Health Educ Res 2007, 22(4):547-560.

29. Coombes L, Allen D, Marsh M, Foxcroft D: The strengthening families programme (SFP) 10-14 and substance misuse in Barnsley: the perspectives of facilitators and families. Child Abuse Rev 2009, 18(1):41-59.

30. Conger RD: lowa Youth and Family Rating Scales on Perceptions of Hostility/Warmth, lowa Youth and Families Project, Wave A (Unpublished technical report). Ames: Institute for Social and Behavioral Research: lowa State University; 1989

31. McMahon RJ, Metzler CW: Selecting parenting measures for assessing family-based prevention interventions. In Drug abuse prevention through family interventions. NIDA Research Monograph 177. Edited by Ashery RS, Robertson EB, Kumpfer KL. Rockville: National Institute on Drug Abuse; 1998.

32. Spoth R, Redmond C, Shin C: Direct and indirect latent-variable parenting outcomes of two universal family-focused preventive interventions extending a public health-orientated research base. J Consult Clin Psychol 1998, 66(2):385-399.

33. Spoth R, Redmond C, Haggerty K, Ward TA: controlled parenting skills outcome study examining individual difference and attendance effects. Journal of Marriage and the Family 1995, 57:449-464.

34. Elliot DS, Huizinga D, Ageton SS: Explaining delinquency and drug use. Beverly Hills: Sage; 1985.

35. Spoth R, Redmond C, Shin C: Reducing adolescents' aggressive and hostile behaviors: randomized trial effects of a brief family intervention four years past baseline. Arch Pediatr Adolesc Med 2000, 154:1248-1257.

36. Zimmerman MA, Schmeelk Cone KH: A longitudinal analysis of adolescent substance use and school motivation among African American youth. J ResAdolesc 2003, 13(2):185-210.

37. Hellandsjo Bu ET, Watten RG, Foxcroft DR, Ingebrigtsen JE, Relling G Teenage alcohol and intoxication debut: the impact of family socialization factors, living area and participation in organized sports. Alcohol Alcohol 2002, 37(1):74-80.

38. Goodman R: The strengths and difficulties questionnaire: a research note. J Child Psychol Psychiatr 1997, 38:581-586.

39. Goodman R: Psychometric properties of the strengths and difficulties questionnaire (SDQ). J Am Acad Child Adolesc Psychiatry 2001, 40:1337-1345.

40. Okulicz-Kozaryn K, Dorozko L: A Polish adaptation of the SFP alcohol prevention program for 10-14-year-olds and their parents [In Polish]. In Promocja zdrowia psychicznego-badania i dzialania w Polsce. Edited by Okulicz-Kozaryn K, Ostaszewski K. Warszawa: Instytut Psychiatrii i Neurologii; 2008:249-262

doi:10.1186/1471-2458-12-319

Cite this article as: Okulicz-Kozaryn and Foxcroft: Effectiveness of the Strengthening Families Programme 10-14 in Poland for the prevention of alcohol and drug misuse: protocol for a randomized controlled trial. BMC Public Health 2012 12:319. 